\title{
The EXIT (ex-utero intrapartum treatment) procedure - from the paediatric ENT perspective
}

\author{
Procedura EXIT (ex-utero intrapartum treatment) - \\ prospettive otorinolaringoiatriche pediatriche
}

\author{
B. PUCHER ${ }^{1}$, J. SZYDLOWSKI' , K. JONCZYK-POTOCZNA², J. SROCZYNSKI ${ }^{1}$ \\ ${ }^{1}$ Department of Paediatric Otolaryngology, Poznan University of Medical Sciences; ${ }^{2}$ Department of Paediatric \\ Radiology, Poznan University of Medical Sciences, Poland
}

\begin{abstract}
SUMMARY
The main principle of the EXIT procedure is to maintain uteroplacental circulation with neonatal anaesthesia by controlled uterine hypotonia. This enables securing the foetal airways and decompress or resect large neck and mediastinal foetal masses. The authors present their experience with use of the EXIT procedure in 7 foetuses in whom evaluation and management of the airways were performed. In 4 patients, the neck mass was surgically removed in the neonatal period, in 1 the propranolol treatment was introduced. Two newborns died shortly after the EXIT procedure. The EXIT procedure allows the paediatric otolaryngologist to provide airway patency of newborns during delivery. Both ultrasound and MR imaging are crucial in the prenatal assessment of foetal head and neck masses. Their application in the evaluation of any foetal anomaly is essential for proper prognosis and treatment. Maternal monitoring for complications such as polyhydramnios and preterm labour are important in planning and desirability of the EXIT procedure.
\end{abstract}

KEY WORDS: EXIT procedure $\bullet$ Foetal neck masses $\bullet$ Foetal airways $\bullet$ Prenatal imaging $\bullet$ Teratoma $\bullet$ Lymphatic malformation

\section{RIASSUNTO}

L'obiettivo principale della procedura EXIT è sfruttare la circolazione uteroplacentare inducendo una anestesia nel neonato e controllando l'ipotonia uterina. In tal modo è possibile garantire la pervietà delle vie aeree e ridurre o resecare grandi masse fetali localizzate nel collo o nel mediastino. Gli autori, in questo lavoro, hanno presentato la loro esperienza di tale procedura in 7 feti. 4 di questi sono stati sottoposti ad asportazione della massa cervivale nel periodo neonatale; in un caso è stato effettuato un trattamento con propanololo; due feti sono morti subito dopo la procedura EXIT. La procedura EXIT permette agli otorinolaringoiatri pediatrici di assicurare la pervietà delle vie aeree durante il travaglio. Sia l'ecografia sia la Risonanza Magnetica sono indispensabili nella valutazione prenatale delle masse del distretto testa-collo, e sono di cruciale importanza per la prognosi e per il trattamento. Altresì importante, ai fini della pianificazione e fattibilità di una procedura EXIT, è il monitoraggio materno di complicanze quali il poliidramnios e il travaglio pretermine.

PAROLE CHIAVE: Procedura EXIT • Masse fetali del collo $\bullet$ Diagnostica prenatale $\bullet$ Teratoma $\bullet$ Malformazioni linfatiche

Cite this article as: Acta Otorhinolaryngol Ital 2018;38:480-484 . http://dx.doi.org/10.14639/0392-100X-1261

(C) Società Italiana di Otorinolaringologia e Chirurgia Cervico-Facciale

\section{Introduction}

The EXIT (ex-utero intrapartum treatment) procedure was initially used for reversing tracheal occlusion in foetuses with $\mathrm{CDH}$ (Congenital Diaphragmatic Hernia). The main principle of the EXIT is to maintain uteroplacental circulation with neonatal anaesthesia by controlled uterine hypotonia ${ }^{1}$. This enables to secure the foetal airways and decompress or resect large neck and mediastinal foetal masses and provide vascular access or cannulation for the ECMO ${ }^{12}$. Allowing the paediatric otolaryngologist to gain adequate control of the airway can thus improve the chances of survival in such cases.

According to Hedrick ${ }^{3}$ the indications for EXIT can be based on the goal of the procedure and at the same time include the type of lesion and diagnosis. The EXIT to airway procedure requires the presence of a paediatric otolaryngologist and is attempts to evaluate and secure the airways during delivery because of the presence of a congenital neck mass with airway obstruction or CHAOS syndrome, or the necessity for reversal of tracheal occlusion. The EXIT to resection procedure involves the par- 
tial or complete surgical removal of the congenital head and neck masses. The other indications are: the EXIT to ECMO (Extracorporeal Membrane Oxygenation) in congenital heart anomalies and the EXIT to separation procedure (in conjoined twins) ${ }^{3}$.

In contrary to the caesarean section, during the EXIT procedure the achievement of tocolysis is the main aim to provide placental support. After hysterotomy, the foetal head and neck and one arm are delivered and the rest of the foetal body and umbilical cord remain in the uterus to preserve heat and fluid loss ${ }^{45}$.

The authors use the airway algorithm to secure the airways as presented by Marwan et al. from Cincinnati Children's Hospital. First, direct laryngoscopy is performed. If not achieved, the next step is to intubate the foetus under control of a rigid bronchoscope with a diameter of 2.5-3.0 mm. In some cases, partial surgical reduction in the tumour mass is necessary. If the intubation is not possible, the ENT specialist performs tracheostomy. After securing the airway, surfactant is administered prophylactically to prevent barotrauma of the lungs and respiratory failure. The newborn is ventilated by the Ambu bag, and before cutting the umbilical cord, the ENT team checks the position of the tracheostomy tube using a flexible bronchoscope ${ }^{1}$.

\section{Clinical cases}

The authors present their experience with use of the EXIT procedure in management of 7 foetuses in whom the evaluation and management of the airways were performed. In 4 patients, the neck mass was surgically removed in the neonatal period and in one propranolol treatment was introduced. Two newborns died shortly after the EXIT procedure.

\section{Case 1. Reversal of foetal tracheal occlusion}

A female foetus with severe $\mathrm{CDH}$ and pulmonary hypoplasia underwent reversal tracheal occlusion with the PLUG (Plug the Lung Until it Grows) balloon (the FETENDO procedure was performed in London - "foetal endoscopic surgery") at a gestational age of 26 weeks. Emergency delivery by the EXIT procedure was performed at 32 weeks of gestation because of unrestrained systolic uterus function and heart rate deceleration. During rigid bronchoscopy, the balloon was removed and the neonate was intubated. The chest X-ray revealed left lung agenesis. The baby died on the $2^{\text {nd }}$ day after birth for severe respiratory deficiency. Postmortem examination confirmed left pulmonary agenesis and right lung hypoplasia due to lack of efficacy of the PLUG balloon (Figs. 1, 2).

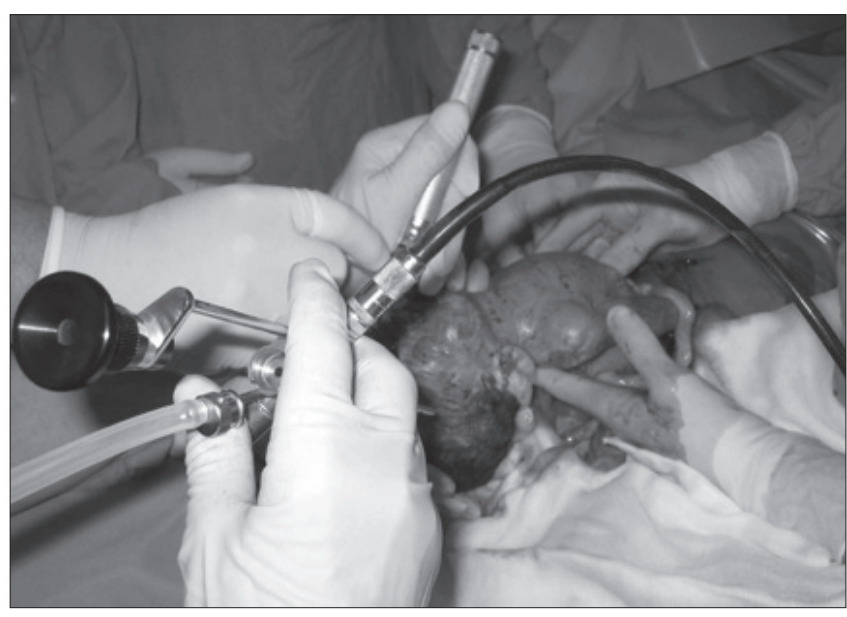

Fig. 1. Rigid bronchoscopy during the EXIT procedure with removal of the PLUG balloon.

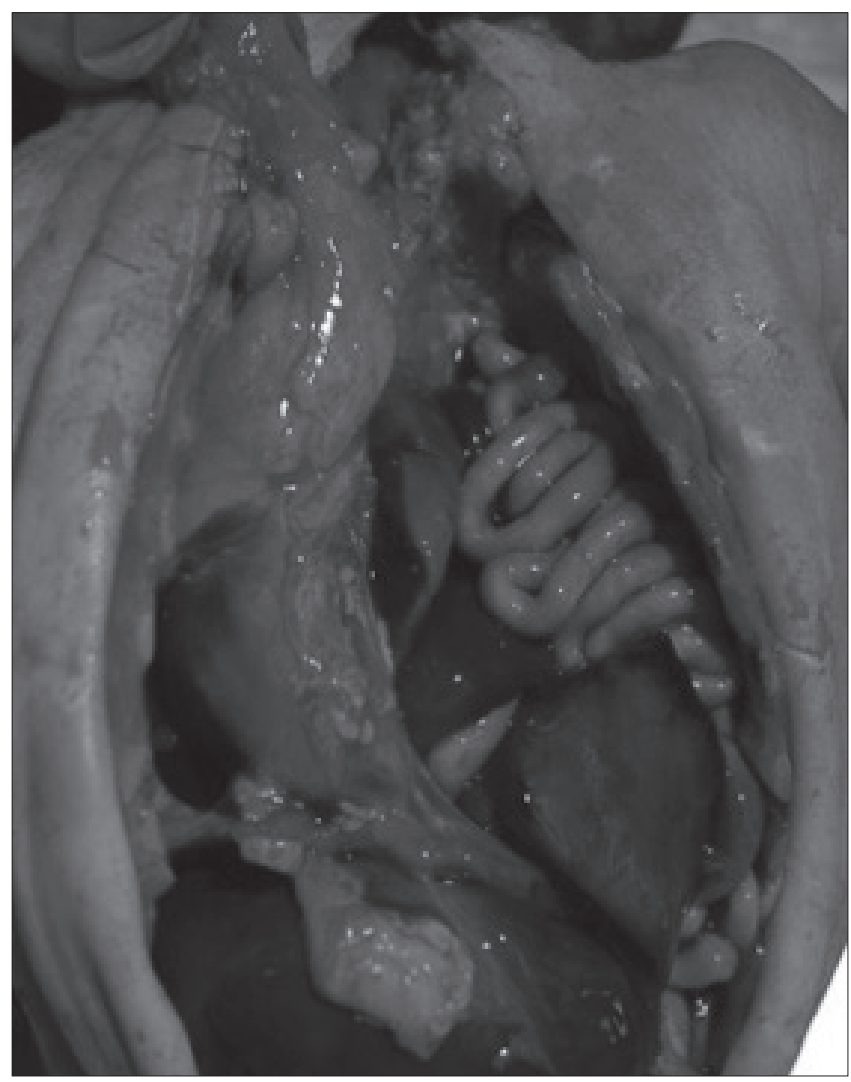

Fig. 2. Postmortem examination revealed severe $\mathrm{CDH}$ and penetration of viscera from the abdominal cavity into the thoracic cavity, left lung agenesis and right lung hypoplasia.

Case 2. Congenital High Airway Obstruction Syndrome (CHAOS)

A female foetus was prenatally diagnosed with laryngeal atresia and polyhydramnios. Parents sought the centre in 
which the child could be born and undergo laryngeal reconstruction surgery. They obtained the consent of the Polish Ministry of Health to fund the labour, the EXIT procedure and laryngeal reconstruction surgery in the US. The only requirement was to maintain pregnancy to 32 weeks. Unfortunately, spontaneous delivery started at gestational week 27 with premature rupture of membranes. The emergency EXIT was performed with tracheostomy attempt. The foetus presented with hydrops fetalis and died shortly after the EXIT procedure. Postmortem examination revealed complete laryngheal and trachea agenesis.

\section{Cases 3-7. Foetal neck masses}

The most common indication for the EXIT procedure in our patients was foetal neck mass, most frequently lymphatic malformations and teratomas. In such cases, prenatal imaging of the neck mass related to airway structures and oesophagus is essential to optimise foetal outcome. In 5 foetuses ( 4 boys and 1 girl), the presence of a neck mass was prenatally diagnosed with ultrasound and MR imaging. It revealed in 2 cases lymphatic malformation, in another 2 teratoma and in 1 infantile haemangioma. In all cases the EXIT procedure was performed. Using direct laryngoscopy or rigid bronchoscopy, the airway was evaluated in all patients. In all endotracheal intubation was performed. Four children underwent complete resection of the neck mass in the neonatal period and the neonate with haemangioma was treated conservatively with propranolol (Figs. 3-5).

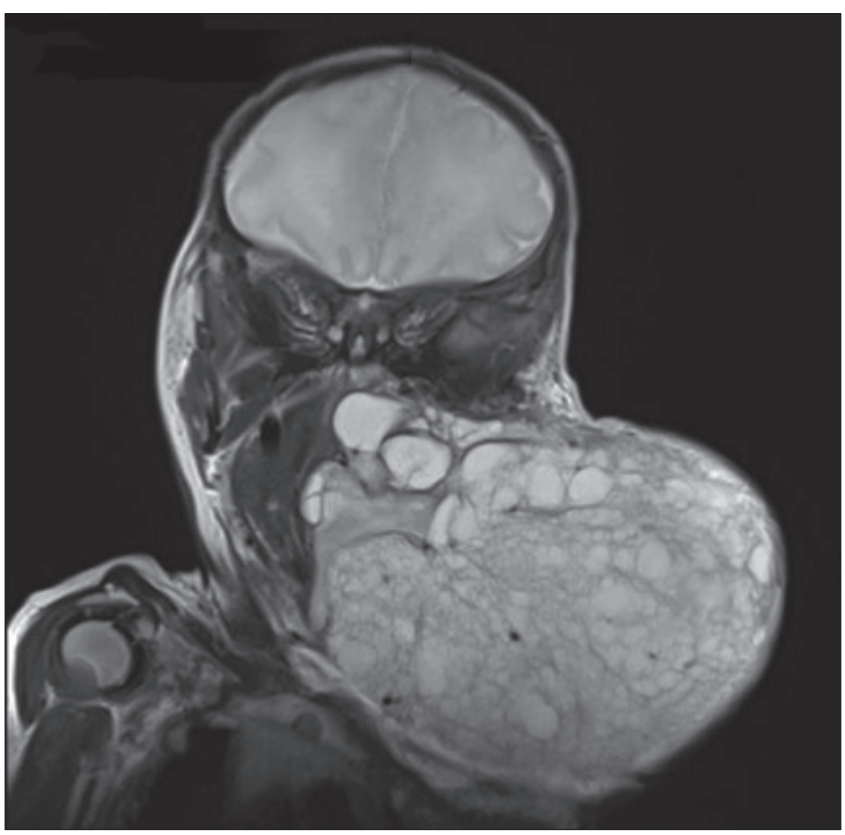

Fig. 3. Neck lymphatic malformation, postnatal MR imaging.

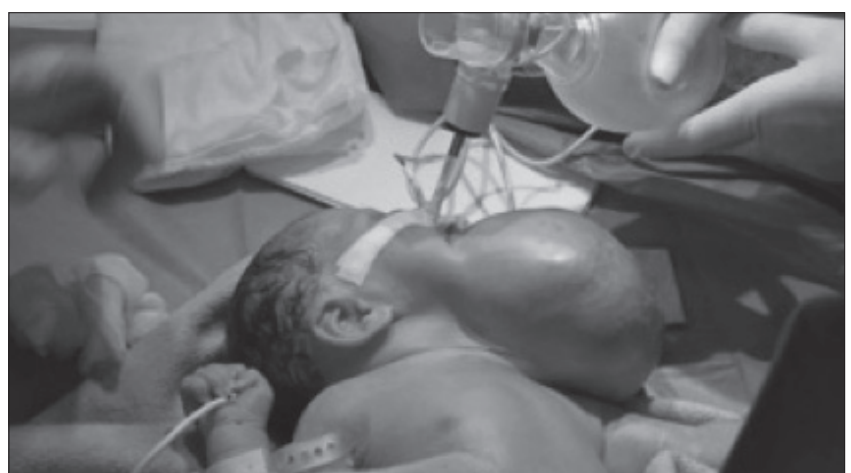

Fig. 4. Neck mass (teratoma) in a female newborn (before surgery).

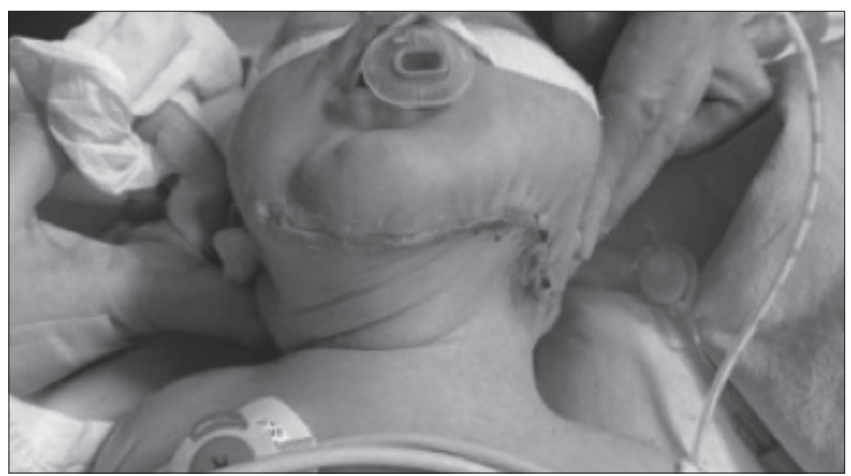

Fig. 5. Neck mass (teratoma) in a female newborn (after surgery).

\section{Discussion}

The EXIT procedure was originally reserved for management of cases with severe $\mathrm{CDH}$ in which tracheal clipping was introduced antenatally. During delivery, the EXIT procedure and placental support provide the surgeon with additional time for removal of the clips, bronchoscopy, intubation and surfactant administration. In the cases presented, the FETENDO technique with use of the PLUG balloon (PLUG - Plug the Lung Until It Grows) was used. It was introduced into the trachea of the foetus with $\mathrm{CDH}$ with extreme pulmonary hypoplasia in order to increase the airway pressure resulting in an increased volume of the lung and alveoli ${ }^{6-8}$.

$\mathrm{CDH}$ occurs in 1:2500 to 1:5000 live births. It has a mortality rate of $20 \%$ and the degree of associated pulmonary hypoplasia and severity of pulmonary hypertension still remain a major determinant of survival. The two factors which clearly influence postnatal mortality are the timing of the termination of gestation and the presence of additional anomalies, which can increase the mortality rate up to $90 \%{ }^{9}$. Foetal surgery, because of its complexity and need for special instrumentation, is available only in a few cen- 
tres that receive a sufficient number of cases. The optimal solution for cases with $\mathrm{CDH}$ is foetal surgery and delivery with the EXIT procedure at the same centre. As emergency delivery and the EXIT procedure were necessary too early (at 32 weeks of gestation) because of heart rate deceleration and $\mathrm{CDH}$ led to severe hypoplasia of both lungs, the probability of survival in the first case was poor.

In the second case presented, the problem of proper qualification to the EXIT procedure occurred. In the foetus, prenatally CHAOS (congenital high airway obstruction syndrome) was diagnosed which is a syndrome with near complete or complete intrinsic obstruction of the foetal airway. It is most commonly caused by laryngeal atresia, subglottic stenosis, laryngeal cyst, or laryngeal web. It may be associated with oesophageal atresia, cardiac anomalies, genitourinary anomalies, vertebral anomalies, imperforate anus, syndactyly and anophtalmia ${ }^{1-38}$. Although the laryngeal and tracheal agenesis was not associated with other anomalies, an increase in polyhydramnios during maternal monitoring was found which worsened the prognostic criteria and therefore the foetus did not have a chance to survive. Although all large neck masses can cause airway compression, the most common indication for the EXIT procedure is cervical teratoma ( 2 of 5 cases presented), lymphatic malformation ( 2 of the presented cases), thyroid goiter, neuroblastoma, neural tube defects and rarely haemangioma (1 of the 5 cases presented $)^{10}$. Lymphatic malformations account for only about $5 \%$ of benign tumours in infants and children. About two-thirds of reported cases are found in the head and neck, usually before the age of 2 years, and some occasionally extend to the mediastinum ${ }^{11}{ }^{12}$. Cervical teratomas are uncommon neoplasms, representing 3\% of teratomas in childhood; $5 \%$ of cases are localised in the head and neck region with a mortality of 40-50\%. Although these lesions are histologically benign, they may be large and may cause airway obstruction (20\% of cases). Prenatal ultrasound diagnosis is possible in early pregnancy (15-16 weeks) ${ }^{13}$. According to Laje ${ }^{13}$ both of these neck masses tend to compress the airway, but in different ways. Cervical teratomas can pull the trachea and lungs superiorly against the thoracic inlet, which can result in pulmonary hypoplasia while lymphatic malformations will not because they are softer. Cervical teratomas, in contrast to lymphatic malformations, can be invasive and destructive causing, for example, mandibular hypoplasia ${ }^{15}$.

At the level of prenatal evaluation, the early involvement of a multidisciplinary team including neonatologist, obstetrician, anaesthesiologist, paediatric surgeon, paediatric otolaryngologist, cardiologist and radiologist is essential to correctly qualify the foetus for the EXIT procedure. Foetal ultrasonography allows visualisation of head and neck malformations and determines their size and localisation. MRI provides information about the relationship of the foetal tumour with adjacent structures such as trachea or oesophagus. It also helps to estimate the severity of the foetal airway obstruction and reveals other anomalies ${ }^{2}{ }^{15}$. Maternal monitoring for complications such as polyhydramnios and preterm labour are important in planning and desirability of the EXIT procedure. Finally, the EXIT procedure allows the paediatric otolaryngologist to provide the patency to the newborn's airways during delivery.

\section{Conflict of interest statement}

None declared.

\section{References}

1 Marwan A, Crombleholme TM. The EXIT procedure: principles, pitfalls, and progress. Semin Pediatr Surg 2006;15:107-15.

2 Liechty KW. Ex-utero intrapartum therapy. Semin Fetal Neonatal Med 2010;15:34-9.

3 Hedrick HL. Ex utero intrapartum treatment. Semin Ped Surg 2003,10:190-5.

4 Sichel JY, Eliashar J, Yatsiv I, et al. A multidisciplinary team approach for management of a giant congenital cervical teratoma. Int J Pediatr Otorhinolaryngol 2002;65:241-7.

5 Zadra N, Giusti F. Ex utero intrapartum surgery (EXIT): indications and anaesthetic management. Best Pract Res Clin Anaesthesiol 2004;18:259-71.

6 Hirose S, Harrison MR. The ex utero intrapartum treatment (EXIT) procedure. Semin Neonatol 2003;8:207-14.

7 Pucher B, Szydlowski J, Blaszczynski M, et al. EXIT (ex utero intrapartum treatment) as a procedure of choice in fetal airway obstruction. Case reports. Stand Med Probl Chir Dziec 2012;2:117-21.

8 Taghavi K, Beasley S. The ex utero intrapartum treatment (EXIT) procedure: application of a new therapeutic paradigm. J Paediatrics Child Health 2013;49:E420-7.

9 De Buys Roessingh AS, Dinh-Xuan AT. Congenital diaphragmatic hernia: current status and review of the literature. Eur J Pediatr 2009;168:393-406.

10 Lazar DA, Olutoye OO, Moise KJ Jr, et al. Ex-utero intrapartum treatment procedure for giant neck masses-fetal and maternal outcomes. J Ped Surg 2011;46:817-22.

11 Colbert SD, Seager L, Haider F, et al. Lymphatic malformations of the head and neck-current concepts in management. Br J Oral Maxillofacial Surg 2013;51:98-102.

12 Stevens GH, Schoot BC, Smets MJW, et al. The ex utero intrapartum treatment (EXIT) procedure in fetal neck masses: a case report and review of the literature. Eur J Obstet Gynecol Reprod Biol 2002;100:246-50. 
B. Pucher et al.

13 Laje P, Peranteau WH, Hedrick HL, et al. Ex utero intrapartum treatment (EXIT) in the management of cervical lymphatic malformation. J Ped Surg 2015;50: 311-4.

14 Stefini S, Bazzana T, Smussi C, et al. EXIT (Ex utero Intrapartum Treatment) in lymphatic malformations of the head and neck: Discussion of three cases and proposal of an EXIT-
TTP (Team Time Procedure) list. Int J Ped Otorhinolaryngol 2012;76:20-7.

15 Stevens GH, Schoot BC, Smets MJW, et al. The ex utero intrapartum treatment (EXIT) procedure in fetal neck masses: a case report and review of the literature. Eur J Obstet Gynecol Reprod Biol 2002;100:246-50.

Received: May 30, 2016 - Accepted: March 21, 2017

Address for correspondence: Beata Pucher, Department of Pediatric Otolaryngology, Poznan University of Medical Sciences, 60, 572 Poznan, Szpitalna 27/33, Poland. Tel. +48 618491363. E- mail: bpucher@poczta.onet.pl 